\title{
COMUNICACIÓN Y MARKETING POLÍTICO COMO ELEMENTOS DE FORMACIÓN ELECTORAL. EL ON Y EL OFF DURANTE LA PRIMERA VUELTA ELECTORAL PARA LA ELECCIÓN PRESIDENCIAL ECUATORIANA EN EL AÑO 2017
}

\author{
ANALYSIS OF POLITICAL COMMUNICATION AND MARKETING \\ THE ELEMENTS OF ELECTORAL FORMATION. \\ THE IN AND OUT DURING THE FIRST ELECTORAL ROUND \\ IN THE ECUADORIAN PRESIDENTIAL ELECTION IN THE YEAR 2017
}

Arturo Virgilio Estrella Osorio', Hugo Renato Palacios Garcia², Kevin D. Calvopiña Panchi

\section{Resumen}

El presente artículo ${ }^{4}$ analiza las características de la comunicación y el marketing políticos como elementos de formación en los votantes, en el contexto de una campaña electoral a escala presidencial. En este caso, el proceso electivo de febrero de 2017 en el Ecuador. La investigación se plantea con el fin de determinar las condiciones y los métodos que las agrupaciones políticas ecuatorianas trabajan en los ámbitos comunicacional y mercadológico, y asi conocer la incidencia en la formación crítica de los electores. A la vez, pretende identificar los parámetros e influencias persuasivas en que ambas líneas de pensamiento se llevan a cabo en las campañas electorales. Para el análisis se utilizó la plataforma Facebook como lugar de campaña en el on (en el cual se presentan y discuten los rasgos y contenidos predominantes). Estos espacios corresponden a los candidatos que obtuvieron las cuatro primeras plazas en la prima vuelta electoral: Lenín Moreno, Guillermo Lasso, Cynthia Viteri y Paco Moncayo.

\section{Palabras clave}

Análisis de campañas, comunicación política, ideologia política, formación electoral, mercadeo político, cyberdemocracia.

Clasificación JEL: M31

\section{Abstract}

This paper analyzes the characteristics of communication and marketing of politicians as elements of voter education, in the context of an electoral campaign on a presidential scale. In this case, the elective process of February 2017 in Ecuador. The research is designed to determine the conditions and methods that Ecuadorian political groups work in the fields of communication and marketing, and thus know the impact on the critical formation of voters. At the same time, it aims to identify the parameters and persuasive influences in which lines of thought are carried out in the electoral campaigns. For the analysis, the Facebook platform is used as a campaign space on the site (in which the predominant features and contents are presented and affected). These spaces correspond to the candidates who obtained the first places in the first electoral round: Lenin Moreno, Guillermo Lasso, Cynthia Viteri and Paco Moncayo. Then the data collection by interviews with a political analyst and two strategies of the currents of thought.

$\underline{\text { Keywords }}$

Analysis of campaigns, Political communication, Political ideology, Electoral training, Political marketing, Campaign process. JEL Classification: M31

\footnotetext{
1 Universidad Central del Ecuador. Licenciado en Administración de Empresas y Máster en Dirección y Planificación Estratégica. artuestrella@gmail.com, avestrellaauce.edu.ec.

2 Universidad Central del Ecuador. Licenciado en Comunicación Social por la Universidad Central del Ecuador. Magíster en Estudios Culturales, con mención en Estudios y Artes Visuales por la Universidad Andina Simón Bolívar. hrpalacios@uce.edu.ec.

3 Estudiante investigador período 2017-2018
} 


\section{Introducción}

Esta investigación aborda el análisis y estudio de la comunicación y el marketing políticos como elementos de formación electoral y su incidencia en los resultados de un proceso electivo, cuestionando los enfoques cuantitativos que se han desarrollado en estudios anteriores sobre el tema. Parte de la premisa de que las agrupaciones políticas ecuatorianas utilizan a ambas ramas del conocimiento, como elementos de promoción (como una venta inmediata) a corto plazo, y no se los maneja como mecanismos de formación y relación (a largo plazo) para y con el electorado; esto influye negativamente en los procesos electorales y los resultados a posteriori, porque restan criticidad al elector. En este sentido se deja de lado la estructuración de una línea de pensamiento permanente en el tiempo, entendiéndose por esto, obtener una victoria (un curul, un cargo, una consulta) obviando los objetivos trascendentales, disminuyendo la opción de lograr ideas comunes en función del beneficio colectivo.

Las investigaciones y estudios realizados sobre esta temática, tanto en el Ecuador como en otros países de la región, se enfocan en un hecho o momento concreto (un proceso electoral en un año determinado, por ejemplo) o bien en un candidato y su campaña, con base en la revisión técnica del mensaje básico, la promoción simple y directa por una victoria (por un resultado), dejando de lado algunos principios básicos tanto de la comunicación como del mercadeo políticos.

Con este antecedente, se planteó la hipótesis de que las agrupaciones políticas trabajan a sus públicos pensando en el resultado a corto plazo, desvirtuando el principio del mercadeo de Kotler y Armstrong (2012) quienes señalan que una idea misional del marketing es "ayudar a construir relaciones duraderas con el cliente creando valor" ( $p$. 4), y dejando de lado la difusión de información veraz y crítica (desechando la base de la comunicación); entonces, se presupone que por errores de estrategia, o por desconocimiento del ámbito global o simplemente porque no se ve necesario el verdadero uso de ambas disciplinas, se trabaja a la comunicación y al mercadeo como elementos utilitarios limitándolos a la promoción.

Hay que tener en cuenta que la comunicación política es un espacio de confines problemáticos que no generan necesariamente ideas o posiciones certeras. Es un saber que se caracteriza por ser interdisciplinario, no solo por los diversos enfoques teóricos, sino también por la importancia de la comunicación, que puede definir una gran victoria o una aplastante derrota electoral. Por lo tanto, para un análisis de este tipo en la era digital no únicamente se necesita insumos teóricos del marketing y la comunicación, sino también de otras disciplinas como la psicología, los estudios culturales, la sociología, antropología, semiótica, historia, entre otras. Álvaro Cuadra, investigador y catedrático, en su texto El Príncipe Posmoderno (2017), sostiene que la comunicación política es, desde hace décadas, un punto crucial en el debate latinoamericano en torno a lo comunicacional. "Esto no es, en absoluto, casual y responde, en última instancia al contexto político regional, inexorablemente signado por la urgencia de sus luchas democráticas" (p. 12).

La propuesta es que la comunicación y el mercadeo políticos deben ser revisados, proyectados y usados como herramientas de formación electoral (masiva, permanente e intensiva) y no como medios de promoción únicamente. Con esto, se espera identificar (o recuperar según el caso) formas y métodos para conectar una propuesta, lograr asi- 
milación (y con esto posicionamiento) de un proyecto político (de un actor político, de un movimiento o partido), más allá del resultado único de la elección inmediata.

La comunicación política, en la actualidad, debe hacerse cargo de una verdadera revolución semiótica, sostiene Cuadra (2017), y que es equivalente a la irrupción de la escritura alfabética hace más de dos milenios. Las transformaciones económico-culturales están reconfigurando radicalmente todo el imaginario histórico social de nuestra época: esto es, los sujetos de la comunicación, la conformación de opiniones y las formas de ejercer el 'control social'. Las nuevas formas de significación obligan a replantear nuestra mirada hacia un horizonte todavía desconocido y que deja más preguntas que respuestas. En ese sentido, la tecnopolítica, la cyberdemocracia y la posverdad pueden apuntalar direcciones que nos permitan si-

\section{Marco teórico y metodológico}

Las investigaciones que algunos partidos políticos realizan, sugieren, que por lo menos un año antes de las elecciones, se debe investigar los deseos y necesidades de la población. La investigación de mercado permite indagar las fortalezas y debilidades de los candidatos, las posibles alianzas y los temas que se deben inflar en campaña. La política moderna es, ante todo, mediática; y es en ese espacio donde se deben pelear los votos duros, militantes, los indecisos y los escépticos. El contacto directo con la población ha quedado relegado a un segundo y tercer plano.

Giovanni Sartori (1998) sostiene que los medios tienden a convertirse en los protagonistas de la información, de esa manera desplazan la influencia de los políticos y, muchas de las veces, del mismo público. El marketing político se ha convertido en una guerra de estrategias e ideas entre partidos y candidatos para conquistar la mente y la tuarnos en el mapa, o quizás, extraviar la brújula política.

Finalmente, es importante entender que la comunicación política que se pasea por todos los escenarios democráticos, es indisociable de las herramientas que el marketing político pone en su maletín y en sus múltiples discursos. No se puede hablar de la primera sin susurrar al segundo, que para bien o para mal, ha impuesto su sello propio.

En el año 2016, el Instituto Nacional de Estadísticas y Censos (INEC) señaló que Facebook es la plataforma online más utilizada por los ecuatorianos con un porcentaje nada despreciable del $69 \%$, seguida por Twitter con un 20\%. En definitiva, el presente artículo analiza si cuatro candidatos de distintas tiendas políticas emplearon de forma adecuada las redes sociales, y en qué medida buscaron electores críticos o susceptibles a la demagogia y al pragmatismo.

voluntad del ciudadano con el fin de ganar o mantenerse en el poder (Valdez, 2002). Si bien el marketing trabaja simbióticamente con disciplinas como la comunicación y la publicidad, la política mantiene, de acuerdo a Mariñez Navarro (2010), puentes con la antropología, psicología, sociología, filosofía, economía e incluso los estudios culturales. Por lo tanto, el marketing debe enlazar estos conceptos para generar una propuesta creíble y verificable. Por ello, todo político y también toda campaña necesita de un proceso estratégico de marketing que logre posicionar las ideas y los planes de quien esté interesado en participar y mantenerse en política.

Este proyecto propone comprobar que se ha transformado el escenario de la comunicación política, y que es importante generar procesos y estrategias de campaña de largo alcance que no solo se sitúen en 
coyunturas electorales, sino que incidan en un electorado consciente a largo plazo. El cuerpo teórico se basará en lo que por hoy se denomina 'la americanización de las campañas', que como señala Díaz Jiménez (2015) "La literatura especializada ofrece diversos términos para referirse a este proceso, como: americanización, mediatización, profesionalización, campañas centradas en los candidatos, orientación de marketing político, entre otros." (p. 1), por lo que, en esta investigación, se toma como referencia inicial, más no única y absoluta, la exitosa campaña electoral presidencial de Barak Obama. Las campañas negativas contra los adversarios, la polémica y el espectáculo son las formas privilegiadas de algunos actores políticos que, hoy por hoy, tienen mucho éxito.

Es importante analizar conceptos como cyberdemocracia, tecnopolítica y posverdad. El estudio de la comunicación política actual requiere de nuevos insumos teóricos que ayuden a comprender y complejizar la política en todas sus fases y aspectos. Una de las claves de por qué la tecnopolítica puede ser un factor de renovación política extraordinaria, sostiene Antoni GutiérrezRubí (2014), no radica solo en la potencia tecnológica para hacer posible y más fácil la participación y la deliberación a gran escala, "sino por la capacidad de reconvertir a los militantes, simpatizantes o votantes en activistas. De hacer posible el tránsito opino-comparto-actúo" (p. 1). Esta interrelación o participación más activa de la ciudadanía gracias a las redes sociales, impone nuevas formas de entender el entramado político, en la que los asesores de comunicación política están en la obligación de actualizarse constantemente y de proponer alternativas a las formas verticales de emitir información.

Se plantea, de igual manera, el abordaje de lo que se conoce como cyberdemocracia, y que apuntalan la importancia y trascendencia del internet como vía para ejercer más democracia y ciudadanía. Lo ideal sería buscar puentes comunicativos, plataformas de diálogo y debate, espacios de negociación virtual transversales y múltiples. Y sin duda, la posverdad, es en la actualidad uno de los conceptos que ayuda a entender la significación política de las democracias modernas. La reciente campaña que llevó a la presidencia a Trump en los Estados Unidos generó una serie de análisis que desembocaron en aceptar que la posverdad se instaló definitivamente en el universo político. Las emociones, la subjetividad, la opinión personal mandan en un momento electoral. Ya no importan las evidencias científicas ni el razonamiento. Quedaron desplazados por la 'lógica de la emotividad', construida por los medios de comunicación y las redes sociales.

En un reciente artículo de The Economist, se manifiesta que la diferencia entre la política de la posverdad y la de la simple mentira es que en la segunda "la verdad no es falsificada o discutida, sino de secundaria importancia", porque de lo que se trata con ella es de 'reforzar prejuicios'. En el artículo enfatiza que con ello se da una impresión de distinción sofisticada pero no es en realidad más que palabreo sin fondo. "No ha habido populista en la historia de la humanidad $-y$, nuevamente, populistas registrados los hay desde Greciapara el que la verdad no sea "de secundaria importancia" y "reforzar prejuicios", la base del éxito." (Berckemeyer, 2017, p. 2).

Las técnicas y estrategias comunicativas son las que deciden el camino y ya no tanto los postulados políticos. La imagen y un candidato carismático, con sentido del humor, cuidado en el vestir (imagen telegénica) son necesarios para impresionar al elector (Sartori, 1998). Para complementar la investigación analizaremos los estudios de recepción, pues estos buscan profundidad en el análisis y explorar los contenidos con mayor rigurosidad. Los ER siguen siendo una opción para comprender a los sujetos 
sociales, las significaciones e interacciones diversas que emprenden con los medios y tecnologías de información. De igual manera, dialogan con los procesos socioculturales en los que se encuentran insertos.

Luis Costa B. será un autor necesario para iniciar el análisis de la semiología política y los procesos semánticos en las campañas políticas. Desde un punto crítico, táctico y pragmático, se trabajará con autores como Guy Durandin, Rafael Reyes Arce, Francisco Javier Barranco y Philippe Maarek, de quienes se tomará los elementos que estructuran una campaña política, así como variables necesarias para estructurar propuestas viables en el tiempo.

La hipótesis a trabajar plantea que la comunicación y el mercadeo políticos son empleados como elementos de promoción a corto plazo, tampoco se los utiliza como mecanismos de formación (voto analítico o 'consciente'), y relación para con el electorado (en el mediano y largo plazos), influyendo esto negativamente en los procesos electorales con sus resultados posteriores.

Se busca identificar si las estrategias de marketing lograron favorecer ciertas tendencias electorales en la red social de Facebook, a la vez identificar los elementos comunicacionales que determinaron $u$ orientaron el voto en los electores, comparando esta información con criterios. Los candidatos y su posicionamiento en redes sociales a ser estudiados son: Paco Moncayo, Lenín Moreno, Cinthya Viteri y Guillermo Lasso. El estudio "Mujer, sexualidad, internet y política" de los consultores políticos ecuatorianos Jaime Durán Barba y Santiago Nieto, publicado en el año 2006, propone un perfil para el elector de América Latina, en el que se destaca, entre otros puntos:

- Recibe información desde las redes sociales.

- Comenta y genera interacción con los datos de las redes.
- Existe una percepción diferente respecto del liderazgo político; el actor no es visto de forma vertical sino horizontal.

- Existe una marcada dirección hacia el placer y el consumo, a la vez que pierde el interés en lo político.

- Existe una predominancia de las líneas de pensamiento de los años sesenta, principalmente en la defensa de los derechos.

Las últimas campañas presidenciales en el Ecuador centran sus esfuerzos en convencer a los electores, a través del marketing y la comunicación políticos, con las tácticas y estrategias de comunicación y publicidad, para lograr el apoyo en un proceso electoral. Los electores son analizados - como si fuesen de compras - como consumidores, sujetos a ser una estadística; en esa lógica entran en juego sus necesidades, sus creencias, personalidad, intereses, incertidumbres y valores, a corto plazo.

Si lo que pretendemos es entender el comportamiento electoral de los electores, y a la vez analizar las estrategias de campaña de cuatro candidatos específicos en la campaña electoral del año 2016, debemos partir con una idea clara sobre la imagen que los electores tienen de los diversos candidatos, así como analizar tanto los componentes externos como internos que generaron razones y emociones para que las personas se hayan decidido por apoyar las tesis, propuestas o 'mentiras' de los cuatro aspirantes a la presidencia.

Losada y Casas (2008) proponen algunos interrogantes que suelen ser tratados por el enfoque tales como: "¿Cómo percibía la persona su entorno inmediato cuando decidió actuar como lo hizo?, ¿Qué creencias tenía?, ¿Qué le motivó a proceder de esta forma?, ¿Cuáles sentimientos explotó un líder político para obtener una determinada reacción popular?". Se intentará dar res- 
puesta a los interrogantes planteados para poder explicar las estrategias planteadas.

Como herramientas de apoyo, el trabajo recurre a entrevistas a profundidad de expertos en los ámbitos políticos y comuni- cacional, que permiten ahondar en el tema propuesto y analizar de mejor manera las distintas campañas electorales por la plataforma de Facebook de los cuatro candidatos seleccionados.

\section{Comunicación, marketing y política en el ámbito electoral}

Los medios no son el único escenario en el que se debe establecer el proceso o la acción política, sin embargo, es necesario hacerlo. Esta afirmación adquiere fuerza, al identificar las dificultades que las agrupaciones políticas encuentran al momento de establecer (o al menos intentar proponer) un mensaje, una idea, que las posicione y las mantenga en el ideario de los electores; así también, los medios no son el único responsable o culpable de la mala imagen de la política y sus actores, pues los errores en las acciones de difusión, coinciden con la percepción negativa de las agrupaciones políticas, y luego, en las formas del quehacer político mismo, que han provocado un declive drástico y permanente de la dinámica electoral.

Es así que los medios llegan a convertirse en instrumentos de conexión, expresión, vínculo y también de influencia entre los actores políticos con los públicos -los electores y no electores - en el proceso de la comunicación y el marketing políticos; el segundo, principalmente, en conjunto con sus herramientas y técnicas de relación, posicionamiento y persuasión, reemplaza el contacto face to face, los 'mitines' y debates públicos, a pesar de que logra una especie de relación directa de los ciudadanos con los candidatos, como mecanismos para establecer la relación entre la idea propuesta con la aspiración. Adicionalmente, la ejecución de sondeos en las etapas iniciales de una campaña política, que luego derivan en pronósticos - no siempre acertados- generan una distorsión del ámbito político, por lo que, a pesar del bombardeo permanente y multimedia, el proceso electoral comunicacional pierde parte de su esencia, pues el elector pasa a convertirse en un consumidor y a la vez en un proveedor de información, es decir en un prosumidor.

La palabra prosumidor -en inglés prosumer-, es un acrónimo que procede de la fusión de dos palabras: producer (productor) y consumer (consumidor). El concepto 'prosumidor' fue anticipado por Marshall McLuhan y Barrington Nevitt, quienes en el libro Take Today (1972), afirmaron que la tecnología electrónica permitiría al consumidor asumir simultáneamente los roles de productor y consumidor de contenidos.

En este punto es pertinente cuestionar, ¿son la comunicación y el marketing, con fines políticos, un elemento útil para formar electores, más allá de tener prosumidores permanentes, es decir, sujetos que comparten, pero no generan información crítica que impacte positivamente en el resultado de la elección?

Para contestar esta inquietud, se analiza inicialmente, que los medios y por ende la comunicación y el marketing políticos, al ser parte de una dinámica cultural y usar elementos masivos y tecnológicos, de forma permanente, con significancia progresiva del internet y las redes sociales, que ha impuesto profundas transformaciones en la ecología cultural de las colectividades modernas, ha transformado los preceptos más elementales de la comunicación misma.

La comunicación política es una ciencia dinámica y participativa que trabaja en 
la generación y entrega de información entre los (oferentes) políticos y sus votantes o electores, a través de los medios de comunicación (Norris, 2002). Si la campaña implica una suerte de ejercicio de comunicación entre los aspirantes a un cargo, en la actualidad esas batallas encaminadas a convencer al electorado utilizan a los medios de comunicación de masas como uno de los principales canales de emisión de mensajes persuasivos. No obstante, las campañas políticas se diferencian mucho, tanto por la intensidad como por las estrategias adoptadas. Si las dos se caracterizan por la audacia y la innovación, ambas no manejan las mismas lógicas.

A menudo se define a la comunicación política como el campo de relaciones contradictorias entre políticos, medios y opinión pública. Los políticos, antiguos, nuevos y en campaña, se sirven de la comunicación, del marketing y la publicidad para decirnos por quién votar, por quién no, a quién odiar y a quién rendirle culto. Se apoyan en investigaciones que señalan la vulnerabilidad de la población, sus gustos y necesidades, deseos y frustraciones. Con esa información, eligen el botón adecuado que suele estar cargado de emotividad, y esperan el resultado.

Habermas (2010) desde la perspectiva comunicacional, señala que "la politización del marco institucional en las sociedades capitalistas avanzadas suplanta a la política que busca una solución de problemas morales, a los que se los puede estudiar mediante la racionalidad comunicativa o simbólica". Este autor añade que, si las tareas del poder político se convierten en tareas técnicas, un control verdaderamente democrático de ese poder, se hace imposible. Por ello, el poder político busca mantener una despolitización de la opinión pública.

En cuanto al marketing, existen similitudes desde el mercadeo de tipo comercial con el político, específicamente en la premisa de una 'venta' de la propuesta que derivará luego en el voto, la influencia en la decisión (compra $=$ voto), el desarrollo y posicionamiento de ideas (es decir, la propuesta y el candidato como productos); la consultoría a escala política considera que el elemento central se orienta a la consecución de votos, sin tomar en cuenta el análisis de las alternativas y peor aún, el cambio de actitudes. Sin embargo, es necesario mencionar que el marketing político, adolece de un carácter ambiguo en el escenario académico, debido a la falta de identidad teórica (limitando su estudio al uso de las herramientas del mercadeo hacia el logro del voto) y luego por la marcada inclinación hacia el proceso electoral, descuidando la idea del relacionamiento (votante cautivo) en el largo plazo (Newman, 1994).

En los estudios actuales de comunicación política ya no se habla tanto de votante o consumidor. El 'usuario' aparece como el concepto que mejor le calza, pues quien se sienta frente a su computador o a su celular pierde la significación convencional que hace algunos años se tenía, por lo tanto es un hecho problemático, "[...] pues, en tanto componente funcional de una red informacional, se trata de una entidad desarraigada; esto es, un usuario - por definición- no está arraigado a un territorio físico, ni a una clase social" (Cuadra, 2017). Por ello, añade Cuadra, nociones clásicas como ciudadanía o participación ya no pueden ser pensadas como en el pasado. De hecho, no se puede establecer, de buenas a primeras, una equivalencia entre 'participación' e 'interactividad':

Las nuevas modalidades comunicacionales de flujos en red están instalando en los usuarios, nativos digitales, nuevos patrones de percepción, pensamiento y acción - habitus - que se oponen a las típicas estructuras verticalistas, burocráticas y normativas en que se desenvuelven los actores políticos. Si pensamos al sujeto "usuario" en su doble dimensión, como componente funcional de una red $y$, 
al mismo tiempo, como ciudadano en un espacio político, podremos advertir la importancia y la profundidad de la mutación en curso. (Cuadra, 2017: 18)

Por lo tanto, si no entendemos los vertiginosos cambios que se dan en el universo digital, difícilmente podremos asimilar cómo se mueve la comunicación política en los distintos escenarios y cómo el marketing logra insertarse en la vida pública sin que nos percatemos de aquello.

\section{Ideología política y opinión pública. Dos conceptos que van de la mano... aunque nadie se da cuenta}

La tan mentada ideología y sus preferencias colectivas con los procesos políticos ha sido motivo de estudio durante mucho tiempo, por lo menos los últimos 50 años. Una de las características fundamentales de la ideología tenía que ver, según una mirada clásica con la legitimación del abuso de poder de las clases dominantes. Según Van Dijk, una de las formas más eficientes del dominio ideológico se da cuando también los grupos dominados aceptan las ideologías dominantes como 'naturales' o como parte del 'sentido común' (Van Dijk, 2005). El mismo Van Dijk hace mención a Gramsci, que llamó 'hegemonía' a tales formas de dominio ideológico, también a Bourdieu, que prefería no usar ese término, pues pensaba que era demasiado vago. La ideología es buena o mala según quién la use y con qué fines. Es ahí donde entra el poder discursivo y simbólico: le da autoridad y legitimidad a quien produce el discurso (Van Dijk, 2005).

Limitémonos a plantear que la ideología sirve para describir creencias específicas, convicciones políticas fundamentales de determinados grupos de personas. Por lo tanto, y concordando con Van Dijk, una ideología es el fundamento de las representaciones sociales compartidas por un grupo social. Habría que preguntarse entonces, si en el caso de los cuatro candidatos seleccionados, ¿hay algún asomo de ideología o el pragmatismo duro y puro es quien gobierna sus ideas y planes de gobierno? César Ulloa (comunicación personal, diciembre de 2017) analista político y docente universitario opina que el pragmatismo puro se evidencia en la estrategia proselitista, eso no quiere decir que los actores carezcan de ideología. Ulloa (2017) piensa que la ideología está presente siempre, la diferencia es que, al llegar al elector, se busca todos los mecanismos posibles para que esas decisiones ideológicas aterricen en una 'caja de herramientas comunicacionales' atractivas y persuasivas, que de alguna u otra manera le inviten al elector a tomar una decisión en las urnas, pero las ideologías existen siempre. Entonces, un grupo de actores políticos que conforman un determinado partido siempre van a tener ideología, sean de derecha o de izquierda, pero como el término no tiene buena fama, prefieren esconderlo.

Guillermo Lasso, candidato que se ubica en la derecha política no habla de ideología, pero su discurso de libre mercado, de abrirse al mundo, conecta sin duda con el liberalismo económico. La derecha ecuatoriana es experta en no tener en cuenta el concepto ideología. 'Las ideologías ya no importan', suelen decir, lo importante es el empleo, el pan y la seguridad para la gente. Su discurso ideológico está presente pero camuflado con una negación que les beneficia. Lenín Moreno, del partido gobiernista, habla un poco de ideología, pero como para completar la frase de los discursos, como relleno necesario. Su accionar y discurso político sigue poniendo énfasis en el Estado. Paco Moncayo tiene un discurso ideológico, sin duda, pero se diluye 
al no querer parecerse al gobierno correísta. Cinthya Viteri, del Partido Social Cristiano, mantiene un discurso firme de libre mercado, de reducción del Estado, de los emprendedores, de la libertad. Queda claro, entonces, que todos tienen una ideología, se incline a cualquier lado de la balanza política, existe, está latente, aunque resulte problemático y poco práctico hablar del tema.

Lo ideológico va de la mano con la opinión pública, cuando de temas electorales se trata. Tanto politólogos, sociólogos, psicólogos, historiadores, entre otros cientistas sociales, coinciden en apuntar que la opinión pública se compone de tres elementos sustanciales: un sujeto colectivo, un objeto que constituye un asunto público (de 'interés general'); y una articulación de ese fenómeno sociocognitivo con el poder político, económico, social e ideológico (Blanch, 1988).

Como campo de estudio e investigación permanente, la opinión pública es medida de forma regular por medio de la técnica de encuesta por sondeo. El fenómeno de la opinión pública aparece como un logro de la llamada modernidad, que busca, por medio de elecciones, una democracia representativa. Conceptos como los de opinión pública, sistemas de creencias, ideologías, comportamientos, actitudes, entre otros, encuentran un valor en la explicación de lo que la gente hace, de lo que piensa, de cómo actúa, a quién sigue y a quién detesta.

¿Los electores ecuatorianos son conscientes al momento de emitir su voto? Desde lejos uno diría que no, que su voto es emocional, pero Ulloa (2017) piensa que el elector ecuatoriano es pragmático, pero que se requiere del trabajo en el ámbito estratégico pues "el pragmatismo puro se evidencia en la estrategia proselitista [...] la diferencia es que al momento de llegar al elector se busca todos los mecanismos posibles para que esas decisiones -ideológicas - aterricen en técnicas comunicacionales atractivas que inviten al elector a tomar una decisión [...]". El ecuatoriano promedio piensa en lo más urgente, en lo inmediato y no se pone a pensar en proyectos políticos a mediano o largo plazo. Alejandro Zavala (comunicación personal, enero de 2018), ex consultor de comunicación del partido CREO, liderado por Guillermo Lasso, opina que el elector es consciente por una sencilla cosa: Debe llegar a fin de mes y solucionar sus problemas, pues "el día a día es lo importante, es decir, satisfacer las necesidades básicas. El ecuatoriano tiene su ideología, que, al parecer, no es estática, puede ser cambiante de acuerdo a las condiciones políticas del momento, de acuerdo a sus urgencias económicas o a sus simpatías por tal o cual candidato".

Alguna vez alguien dijo en son de broma que la opinión pública es lo que la gente cree que la gente cree, es decir, dejarse llevar por lo que la mayoría piensa o lo que los analistas, periodistas y gobernantes opinan. Hoy en día, gracias a las TIC eso se vuelve problemático. Los ciudadanos ya no son simples receptores, pasaron a ser prosumidores, con un criterio no siempre homogéneo; y ahora con el concepto de usuario el tema se complica y el debate se amplía, como lo sugiere Álvaro Cuadra en El príncipe digital.

En esa perspectiva, ¿podemos hablar de que la comunicación política y el marketing ayudan a formar electores? ¿Es esa su misión? ¿O simplemente sirven para manipular conciencias en el momento de las elecciones? ¿Se comporta el elector como una masa o como un público? Cuadra sostiene que la experiencia histórica reciente parece indicar que, en efecto, estamos ante públicos capaces de forjar una opinión que se transforma en acciones políticas. En este punto, añade, nuestra hipótesis apunta a que las nuevas modalidades comunicacionales de flujos en red están instalando en los usuarios, nativos digitales, nuevos patrones de percepción, pensamiento y acción -ha- 
bitus - que se oponen a las típicas estructuras verticalistas, burocráticas y normativas en que se desenvuelven los actores políticos (Cuadra, 2017). Si pensamos al sujeto 'usuario' en su doble dimensión, como componente funcional de una red $y$, al mismo tiempo, como ciudadano en un espacio político, podremos advertir la importancia y la profundidad de la mutación en curso. Ulloa explica que es indudable, la comunicación política en la actualidad es determinante. Porque si se tiene un elector que está obligado a trabajar más y vivir menos, es necesario buscar mensajes que simplifiquen lo que el candidato dice. Si la gente llega en la noche cansada no va a leer 20 o 30 páginas de un programa de gobierno. La gente busca mensajes que sean orientadores en cuanto a la posible adscripción a determinado político o partido, pero tampoco quiere decir, por ejemplo, en el caso de las redes sociales, que haya un estudio que determine que hay influencia directa en esas decisiones.

Zavala (2018) piensa que es importante la formación del electorado, que se debe estar en contacto con la gente, generar libertades. Que las personas entiendan por dónde camina el partido. La realidad ecuatoriana parece advertir que a los partidos políticos muy poco o nada les interesa la formación de electores. Sus estrategias comunicacionales y de marketing solo apuntan a la inmediatez y a mensajes pragmáticos, sin pensar en una estructura de mediano y largo plazo. Es indispensable que los partidos formen a su electorado; partido viene de 'parte', es decir, alguien que se inscribe en una organización política está tomando postura sobre algo en la realidad y eso significa que el partido, al tomar una postura sobre determinadas cosas, está diciéndole a sus electores, por ejemplo: "un modelo de país debe ser orientado sobre determinadas características". Esta es una obligación de los partidos. El problema es que en el Ecuador no ha habido partidos como en la democracia liberal de corte occidental.

¿Pueden entonces las nuevas tecnologías convertir a nuestras endebles democracias en cyberdemocracias?

\section{Cyberdemocracia a cuentagotas, tecnopolítica y la posverdad como nuevo mandamiento}

Es importante afirmar que en los últimos años algunos analistas de comunicación sostienen que la inserción de las nuevas tecnologías podría tener un efecto hasta revolucionario en cuanto a la influencia política de nuestras democracias. Esta visión optimista choca con otras perspectivas que miran al aparecimiento de las TIC como un mal que solo pretende convertirse en una herramienta para distraer a las masas y manejarlas de forma más eficaz.

Uno de los estudiosos de este tema es R. Davis (1999), quien afirma que, a pesar de lo masivo de las nuevas tecnologías, sin embargo, sigue siendo una minoría la que se preocupa, opina e interviene en temas políticos y sociales. La gran mayoría, afirma, se complace con temas lúdicos: vídeos, memes, comicidad, chismes. Davis sostiene que los diversos actores del espectro político serán readaptados como nuevo instrumento de los habituales objetivos de propaganda, marketing político y visiones estereotipadas de la realidad.

A pesar de aquello, el autor piensa que los dirigentes políticos sentirán otro tipo de presiones y de exigencias ciudadanas, que obligará a que cambien la mecánica comunicacional de su actividad política. Hay quienes ya hablan de cyberdemocracia, y que apuntalan la importancia y trascendencia del internet como vía para ejercer más democracia, más ciudadanía. Lo ideal sería 
buscar puentes comunicativos, plataformas de diálogo y debate, espacios de negociación virtual transversales y múltiples. ¿Es posible tanta maravilla?

El marketing y la propaganda institucional se llevan la medalla de oro al momento de establecer líneas directrices en el ámbito político, pues tomando en cuenta la estructura así como la normativa electoral aplicable a los procesos políticos, la comunicación limita la - verdadera- participación ciudadana pues es necesario contar con el respaldo - aval - de una entidad política que facilite la difusión de una propuesta.

A pesar de esta afirmación que mira posibilidades de crear nuevas formas de comunicación por la red entre los ciudadanos y los dirigentes políticos, lo que a diario se observa en las redes sociales es una saturación de información que marea al más entendido, y que siguen siendo los interesados en política, es decir, los convencidos, quienes interactúan y proponen. ¿Pero qué pasa con el grueso de la población? ¿Cómo lograr que se empoderen de los temas que les deberían interesar? ¿Es posible encauzarlos en esa corriente cuando lo importante para un gran segmento de la población es la sobrevivencia diaria y para los jóvenes, el entretenimiento y las redes para fines más bien superficiales? Quizás las redes sociales se convierten en muchos de los casos es una herramienta para el embrutecimiento colectivo y en donde, a decir de Umberto Eco, citado por Roque Román Latorre (2017) en el Diario El Comercio de la ciudad de Quito en que "... le dan derecho de hablar a legiones de idiotas". Y con legiones de esa naturaleza construir ciudadanía se pone cuesta arriba.

Dicha construcción requiere de la participación activa de la ciudadanía, lo que implica educar a las nuevas generaciones en ese sentido, implementar planes de estudio que pongan énfasis en la trascendental importancia de empoderarse de eso que lla- man ciudadanía, y que para las grandes mayorías en nuestro país es un término vano, y que más bien les sirve a los políticos de turno para vaciarla de contenido.

El catedrático español José Luis Dader (2003) sostiene que la masa indeterminada de los ciudadanos de a pie sigue relegada al papel de espectadores distantes y por lo general desorientados, sin efectividad real de ejercer sus apetencias o derechos comunicativos individuales; "salvo que cada ciudadano acepte la previa cesión de su afán reivindicador a alguno de esos colectivos intermedios que por lo general los administrarán también de manera sectorial y corporativizada" (Dader, 2003). En contextos como los nuestros, la brújula la tienen todavía esos grupos de interés, a los que no les conviene que la ciudadanía ejerza su derecho a convertirse precisamente en ciudadano. El marketing y la propaganda hacen el trabajo sucio y los políticos deciden - bien lavados la cara- qué decisión es la mejor para los ciudadanos que nunca se enteraron de lo que ellos decidieron.

Para Castells (2012) los movimientos sociales del siglo XXI se están organizando no solo dentro de la llamada sociedad red, sino también dentro de una estructura comunicativa basada en redes horizontales de comunicación interactiva, inalámbricas y multidireccionales. En este sentido, las redes sirven no solo para construir, dinamizar y coordinar la movilización en las calles, sino que también se han transformado en una plataforma que estructura nuevos pensares y sentires. La tecnopolítica plantea, entonces, una diversidad de estrategias de acción y organización social que revolucionan las formas de comunicarse.

En el caso ecuatoriano no podemos hablar de cyberdemocracia, pues para entablar esa reflexión se tiene que consolidar el e-government que en el país no existe. Cuando un ciudadano empieza a interactuar 
con el gobierno, se ponen trabas, a través de una serie de artilugios tecnológicos desde el ámbito digital o cuando faltan cosas tan básicas como cumplir la Ley Orgánica de Trans-

\section{Análisis y diagnóstico estratégico}

Para el análisis de este artículo, se estableció una línea de trabajo, en la que se identifica distintos componentes utilizados en la campaña política, desde el escenario on (el mundo virtual, es decir la campaña a través de redes sociales, fan page, páginas web y otros medios digitales) para luego comparar esta información con datos y criterios desde el off (los medios o espacios tradicionales); esto permite cotejar tanto el uso de las herramientas o TIC con la acción que, en relación a estos, se lleva a cabo en otros escenarios. Así, primero se diseñó una matriz o ficha para recopilación de datos en la plataforma de Facebook, como primer elemento táctico; entre las variables propuestas para la medición se seleccionó:

a. Identificación-candidato (identificación por nombre y apellido).

b. Identificación-agrupación política.

c. Fecha de posteo (fecha en la que subió información a la plataforma).

d. Link (dirección textual de acceso a directo a la publicación).

e. Textos del posteo (contenido textual de la publicación).

f. Hashtags (etiquetas de conversación utilizadas).

g. Discurso político unificado (mensajes estratégicos sobre los temas más importantes de la propuesta o de coyuntura).

h. Tipo de producto (elementos complementarios como video, infografía, mi- parencia de Acceso a la Información y cuando un alto porcentaje de las instituciones no 'cuelga' los documentos para informar en qué se están usando los recursos.

crovideo, fotodato, foto informativa, animación, foto).

i. Tema (tópicos y grupos abordados en la publicación como: político, cultural, ambiental, género, económico, trabajo, salud, educación, vivienda, niñez juventud, ancianos, corrupción, familiar, diversión, transporte, madres, turismo, seguridad).

j. Códigos sociales (aborda las formas en el trato para con los otros actores de la publicación: formas de hablar, manos o gesticulación, besos, expresiones faciales, gestos, moda y vestimenta, posturas, protocolos, rituales, saludos, señas, otros comportamientos).

k. Códigos ideológicos (las bases de la propuesta planteada: patriarcado, individualismo, corrupción, libertad, capitalismo, progreso, cambio, revolución).

l. Tonos (complementario al código social, ejemplifica o amplía las formas de la propuesta: agresivo, confrontador, sarcástico, esperanzador, divertido, negativo).

m. A quién/es le/s habla (grupo o segmento al cual va dirigido al mensaje: jóvenes, niños, jóvenes adultos, adultos, madres, padres de familia, mujeres, masivo o abierto).

En la tabla número 1 se presentan las variables utilizadas. 
Cuadro1. Matriz de Recopilación en Facebook

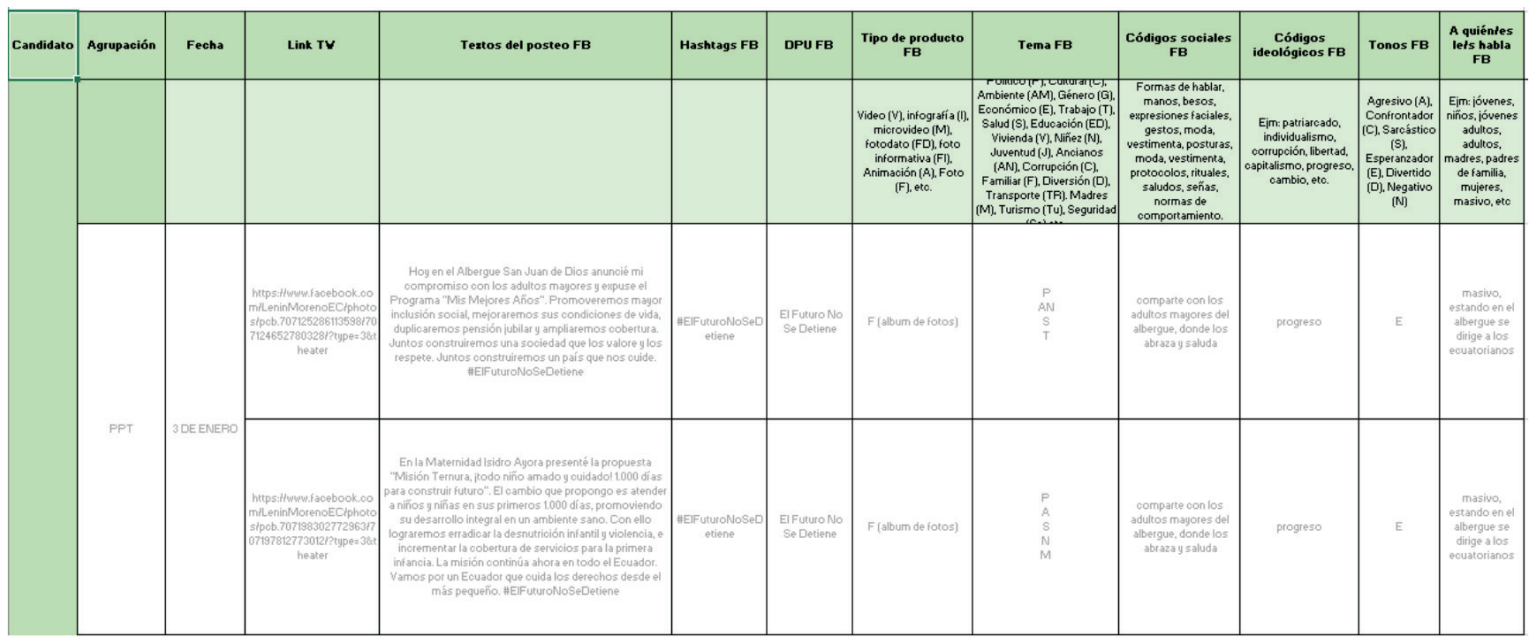

Fuente: Matriz basado y tomada del artículo Análisis del discurso político en Twitter. Un estudio comparativo de las estrategias discursivas de los candidatos finalistas a la Presidencia de Ecuador en 2017. Natalia Angulo y Arturo Estrella. 2018

Entre los cuatro candidatos evaluados, durante un período desde el 3 de enero al 19 de febrero del año 2017, se registraron 332 publicaciones, siendo Lenín Moreno el primero con 107 posteos, Paco Moncayo el segundo con 86, Cinthya Viteri con 84 y Guillermo Lasso, el último, con 55. El orden de esta escala, no es igual al resultado de la contienda electoral.

La segunda herramienta táctica seleccionada fue la entrevista, que se utilizó en dos espacios diferentes; el primero desde el análisis externo y desde el ámbito académico con el Dr. César Ulloa, catedrático de la Universidad de las Américas y analista polí- tico, y luego desde el estratégico operativo en campañas políticas y electorales con expertos de dos agrupaciones políticas, como el caso de Alejandro Zavala (2018), consultor político y asesor de Movimiento Sociopolítico CREO (de tendencia centro derecha) y con Roberto Wohlgemut (comunicación personal, febrero de 2018), consejero de gobierno en comunicación política de la Presidencia de la República durante la presidencia de Rafael Correa. Las preguntas abarcaron de manera directa, tópicos como la misma ideología, el análisis de las campañas, el uso de las redes u otras TIC, entre otros puntos.

\section{Hallazgos}

\section{La ideología aún existe, pero se adapta a nuevos escenarios}

El principal hallazgo de esta investigación no es únicamente ratificar la existencia de líneas políticas basadas en la ideología, sino el hecho de conocer, tanto por las entrevistas a los analistas y gestores estratégicos de los dos principales movimientos políticos del Ecuador, como por la revisión de los mensajes en la red social Facebook (que incluyó 160 men- sajes de los candidatos que obtuvieron los dos primeros lugares y 170 de Viteri y Moncayo, todos publicados entre el 03 de enero y el 16 de febrero de 2017), que las ideas (con las propuestas como elemento visible de estas) son trabajadas de forma similar por los actores políticos, diferenciándose en que la línea de pensamiento opositor (las dos agrupaciones 
de centro derecha) promueven su pensamiento de manera sutil pero más directa, respecto de las dos agrupaciones de centro izquierda o izquierda-izquierda que no hacen menciones sobre sus postulados ideológicos o si lo hacen, es de manera superficial. Se ratifica entonces, la premisa base de esta investigación referente a que el marketing y la comunicación política no son utilizados para formar electores y que, a pesar de que existe el interés de generar formación y consciencia en el target - es decir personas que meditan el resultado a mediano y largo plazo de su voto- las propuestas se desarrollan con base en una o varias necesidades inmediatas del grupo elector.

Esta afirmación es ratificada por ambos expertos (Ulloa y Zavala), cuando señalan de manera directa que el elector ecuatoriano no es consciente, pues su voto se decide y orienta según la coyuntura (influenciada directamente hacia el plazo inmediato) social y económica que a su vez se relaciona con la realidad, es decir, "el elector siempre va a decidir lo urgente sobre el mediano y largo plazo" en palabras de Ulloa (2017). Este fenómeno se comprueba también al momento de revisar la matriz diseñada para este estudio, dos de los cuatro candidatos envían mensajes ideológicos sutiles hacia sus electores y el público en general; uno de cuatro apenas hace menciones (difusas y casi imperceptibles) y el último no hace alusión alguna. Coincidencialmente, los dos candidatos de centro derecha, Guillermo Lasso y Cinthya Viteri, trabajaron algunos de sus mensajes promoviendo algunos lineamientos de sus respectivos movimientos, desde el liberalismo económico, pasando por los sistemas de valores basados en la familia, hasta llegar a mensajes sobre la importancia de la libertad de pensamiento y acción, fortaleciendo sus ideas con explicaciones sobre las ventajas del modelo político propuesto, mientras que Lenín Moreno y Paco Moncayo, se concentran más en ideas con carga emotiva más fuerte (el sentimentalismo como elemento de decisión) sin mencionar los preceptos de izquierda a la que representan, siendo Moreno el que más trabaja en mensajes ratificando el modelo del rol del Estado como principal eje de desarrollo. Sobre Moreno, es importante señalar que la campaña tomó un tinte más emotivo, por una parte por la proyección de imagen soft o suave (comparando esta con Correa como presidente antecesor) pero a la vez por los postulados del movimiento Alianza País en que, de acuerdo a lo señalado por Wohlgemut (2018), la ideología se transmitió permanentemente durante los 10 años de gobierno correísta.

\section{La ideología en el post, un concepto adaptable}

El hecho de pertenecer a la línea política opositora, motiva a que los candidatos Lasso y Viteri, expongan ideas con explicaciones más amplias - sin que esto implique precisas y mejores - sobre como llevarán a cabo sus propuestas de campaña (por ejemplo, en el caso de la creación de fuentes de empleo o el acceso a vivienda). En este punto, tanto Ulloa como Zavala coinciden al afirmar que los mensajes deben ser fuertes, pues no es sencillo que el grupo elector olvide 10 años de campaña permanente por parte del correísmo. El uso de la palabra 'cambio' como elemento básico de los mensajes y luego reconvertido en componente ideológico de los cuatro candidatos (incluyendo a Moreno, quien fue Vicepresidente del Ecuador durante la primera mitad del mandato de Correa) es usual y permanente en más del $85 \%$ de los mensajes promovidos; es este valor, 'cambio', el que busca orientar el voto de los electores, pero sin apegarse a ninguna línea de pensamiento específica, es decir, la palabra sola no transmite una línea ni una dirección a la cual deba dirigirse el elector. 


\section{Del elector consciente al elector colaborador}

La importancia del elector para con el proceso político es una idea obvia, pero, ¿cuánta atención prestan las organizaciones políticas a sus votantes? Desde el punto de vista 'operativo' el elector demanda actualmente que sus ideas - no solo sus necesidadessean tomadas en cuenta para el diseño y promoción de propuestas electorales. En este punto, Zavala (2018) menciona que la campaña y con ello la comunicación derivará en un ámbito colaborativo, lo que en líneas anteriores abordamos desde el concepto del prosumidor, porque "[...] hacemos o hagamos todos la campaña [...] la gente es protagonista de la campaña, es parte de la campaña, hace la campaña, 'edita' y puede influir en la campaña [...]"; sin embargo, basando la teoría, más la premisa expuesta por el experto así como la interacción identificada en los comentarios de los seguidores a las publicaciones de los candidatos, proponemos una transición del elector al proelector, es decir, aquel elector que participa (interactúa) en la conformación de la propuesta política, que luego direcciona estas actividades y finalmente participa del proceso electivo. Esta 'proelección' potencia la idea de que existe una necesidad mutua, es decir, la agrupación política requiere también del grupo elector no solo por el voto sino porque estos

\section{La decepción como factor de voto}

Tanto Ulloa como Zavala sugieren que el elector ecuatoriano no es consciente, y como se mencionó en líneas anteriores, esto se debe no solo a la coyuntura social y económica que desde hace algunos años atraviesa el Ecuador, sino también a las continuas y permanentes decepciones políticas generadas por los diferentes gobiernos y sus ideologías (desde los modelos neoliberales de las décadas de los años ochenta y noventa hasta el actual sistema de corte se están convirtiendo en entes interactivos del proceso mismo, que esperan no solo respuestas directas de los candidatos sino que estos los reconviertan (incluyan) como parte misma de su campaña. Es así, que la línea ideológica 'se mueve', pues el elector no solo acepta la idea de la agrupación y el candidato, sino que espera ser parte activa de esta. Inmediatamente, surge un micro debate, en el que se ponen de frente la comunicación con el marketing, en el que tomando en cuenta este nuevo rol del elector (que ya no es solo consciente sino semiconsciente pero interactivo) se necesita determinar cuál de las dos ramas genera una influencia más fuerte y específica en el proceso político; nuevamente, la teoría, los criterios y la información obtenida en las redes, ratifican que ambas deben trabajar en conjunto, pero orientando un poco más la balanza hacia lo comunicacional, debido principalmente a dos situaciones. La primera es que el mensaje debe ser estructurado basándose en un adecuado 'mapeo' de las necesidades y recordando que la política misma es un ejercicio de permanente comunicación; y, la segunda, es que el marketing mismo demanda de comunicación para lograr el establecimiento de la relación agrupación política + elector.

socialista); la respuesta a la decepción más los problemas inmediatos, logran que a pesar de las manifestaciones populares, se vea al elector como desinteresado de la cosa política (ejerce el sufragio, pero no medita el voto pues el resultado es el mismo) y en muchos casos inclusive prefiera no participar de esta. Por esto, el discurso político unificado y luego los slogans y las propuestas mismas de campaña, trabajan no solo en la demostración (recordación) de los proble- 
mas y las necesidades sino en el rol que el elector tendrá en el proceso y el resultado

\section{Conclusiones}

a. Las ideologías políticas siguen vigentes, pero estratégica y tácticamente, los procesos políticos y electorales trabajan hacia el plazo inmediato, debido a factores como los momentos coyunturales de los electores, el proceso de financiamiento permanente que demanda el sostener a una agrupación política y luego el proceso político de esta misma. Adicionalmente, desde las respuestas de los expertos (que son críticos de que otras agrupaciones trabajen de esta manera) así como de los comentarios de los electores en redes, se puede evidenciar que el discurso, el mensaje y la propuesta son estructurados para grupos masivos que no entienden el impacto de su decisión en el mediano y largo plazo, es decir, que es preferible mantener al elector como está (sin el ejercicio de analizar su voto) y no prepararlo en función de los escenarios futuros.

b. Se ratifica la importancia y la necesidad de formar electores conscientes, que no solo piensen en el resultado $a$ posteriori de su elección, sino que se convierta en un grupo al que se debe formar (capacitar en términos técnicos, políticos, sociales) para que sean personas más activas, permanentes, determinantes y participativas del proceso político. Esta propuesta es a la vez inclusiva, pues la idea es que las diferentes líneas de pensamiento político adopten (y no solo adapten) su sistema de valores tomando en cuenta la diversidad sexogenérica, etárea, cultural, entre otras, pues la heterogeneidad es cada vez más amplia y por ende com- de la elección, tratando de dejar a un lado la apatía y la decepción.

pleja, lo que demanda que la acción política conozca las nuevas realidades, las entienda, respete y promueva. Esto motivará la creación de planes programáticos más objetivos con enfoques por una parte novedosos, pero más cercanos al quehacer diario de los grupos a los que se dirige la propuesta.

c. A pesar de que la figura política del outsider es interesante para el electorado y necesaria para el proceso político, cualquier propuesta debe contar con lineamientos que permitan trabajar y desarrollar criterios técnicos pero fáciles de ser llevados hacia los grupos heterogéneos. La libre elección con base en el libre pensamiento, debe mantenerse y reafirmarse, pero es pertinente y obligatorio que se genere modelos de liderazgo profesional; al hablar de profesionalismo nos referimos a personas preparadas y que entiendan tanto el rol de la persona política como de la persona que ejerce la función pública, además de que el discurso y las acciones vayan más allá de la motivación simple, y que promueva precisamente la identificación de nuevos sujetos políticos, nuevos líderes que a su vez incentivan en sus grupos el interés por la acción política y la necesidad de involucrarse, la necesidad de pensar en el voto.

d. En términos del marketing, hablando de la generación y transmisión de experiencias de los clientes, la idea vigente y próxima es trasladar y utilizar esta idea hacia el escenario político, en el que se debe generar esas vivencias y experiencias a los electo- 
res incluyéndolos en toda la conformación de la propuesta de campaña e inclusive en la estructuración de los mensajes. La idea del prosumer, que interactúa con las marcas y que incide en los productos y servicios, se puede utilizar políticamente y convertir al votante en un proelector que interactúa con las agrupaciones políticas y luego incide en el desarrollo de las propuestas. Esta incidencia a su vez generará modificaciones en el desarrollo de los discursos e inclusive en la forma de pensar de la agrupación política y de los candidatos. La participación y colaboración permanentes de los proelectores no solo deben abordarse desde un escenario online sino desde el off, puesto que la decisión del voto no solo se trabaja en escenarios virtuales, sino también en reuniones, diálogos directos y el todavía uso de los medios tradicionales.

e. Los políticos ecuatorianos aún no están en la palestra para usar y mostrarse en redes sociales, no tienen una identidad desarrollada, él único que pudo acercarse a esta identidad es Correa, pero ha ido disminuyendo su interactividad. Muchas personas y los mismos consultores mantienen que para llegar a las personas lo importante es la cantidad de interacciones o reacciones que generó, pero no solo debe ser lo cuantitativo, sino una mezcla entre cualitativo y cuantitativo. Zavala (2018) sostiene que es más factible hacer una interacción face to face, acercarse al pueblo. Además, llevar una vida equilibrada entre cómo se muestra un político en redes y cómo es 'normalmente'. Lo que verdadera- mente ha generado las redes sociales es la horizontalidad.

f. Es importante profundizar en el concepto de usuario como componente funcional de una red informacional. Álvaro Cuadra observa que se vuelve importantísimo que la comunicación política actual no pierda de vista la complejidad de actuar en el mundo digital, ya sea como masa o como público, y las nuevas formas de control social, que pueden ser disfrazadas de 'participación'. De hecho, no se puede establecer una similitud entre participación e interactividad, cuando el usuario no tiene una territorialidad ni una clase social. Se puede pensar que con las redes sociales la comunicación se ha vuelto más horizontal, sin embargo, no hay que dejarse llevar por cantos de sirena. Si las redes son vistas con tanto optimismo, lo más saludable es sospechar de ese 'beneficio' social, a riesgo de ser visto como pesimista.

g. Los políticos ecuatorianos y los partidos a los que representan no tienen un plan estructurado sobre formación política a mediano y largo plazo. Los electores son buscados, por medio del marketing y la comunicación política, únicamente para fines electorales. El pragmatismo es la receta preferida y constante. Parece que los actores políticos y cuadros dirigenciales tienen una enorme pereza ideológica cuando se trata de temas profundos y de largo plazo. El inmediatismo es el principio y el final de sus planteamientos. Ganemos y luego veremos parece ser la consigna, pero a la final del día, muchos de los electores terminan convertidos en clientela política. 


\section{Referencias}

Barranco, F. (2010). Marketing político y electoral. Madrid: Pirámide-ESIC.

Barredo, D. (2014). Interacción Institucional, participación democrática y transparencia. La iniciativa del Voto Transparente en el Ecuador (2013-2014). Chasqui 126. Comunicación Organizacional. Quito-Ecuador.

Berckemeyer, F. (2017). La mentira de la Posverdad. Lima. Revista UNO.

Bilancio, G. (2008). Marketing: las ideas, el conocimiento y la acción. Ciudad de México: Pearson Educación.

Blanch, J. M., Elejabarrieta, F. J. y Muñoz, J. M. (1988). Ideología y política. Madrid: Pirámide.

Castells, M. (1997). La era de la información. Economía, sociedad, cultura. Madrid: Editorial Alianza.

Chaves, N., (1988). La imagen corporativa. En Teoría y metodología de la identificación institucional. Barcelona: Gustavo Gilli.

Costa Bonino, L. (1994). Manual de marketing político. Montevideo: Editorial Fin de Siglo.

Cuadra, A. (2017). El príncipe en la era digital. Recuperado el 4 de enero de 2018 de file://C:/Users/Amelia/Desktop/EL\%20 PRINCIPE\%20\%20DIGITAL.pdf.

Dader, J. L. (2003). Cyberdemocracia y comunicación política virtual. Barcelona: Ariel.

Davis, R. (1999). The Web of Politics. The Internet's Impact on the American Political System. Nueva York: Oxford University Press.

Díaz Jiménez, O. F. (2015). Marketing político y profesionalización de las campañas electorales presidenciales del Partido Acción Nacional y del Partido de la Revolución Democrática, 1994-2006. Ciudad de México: Revista Polis.

Durán Barba, J. y Nieto S. (2006). Mujer, sexualidad, internet y política. Los nuevos electores latinoamericanos. Ciudad de México: Fondo de Cultura Económica.

Durandin, G. (2001). La mentira en la propaganda política y en la publicidad. Barcelona: Paidós.

Fagen, R. (1971). Política y comunicación. Barcelona: Paidós, Centro de Investigaciones Sociales.
Ferrell, O. y Hartline, M. (2012). Estrategia de marketing. Ciudad de México: Cengage Learning.

Ferrés I Prats, Joan (2014). Las pantallas y el cerebro emocional. Barcelona: Gedisa. Foucault, M. (2012). Vigilar y castigar. Madrid: Biblioteca Nueva.

Gramsci, A. (2003). Notas sobre Maquiavelo. Sobre la política y el Estado moderno. Buenos Aires: Nueva Visión.

Grimson, A. (2010). Los límites de la cultura. Buenos Aires: Editorial Siglo XXI.

Gutiérrez Rubí, A. (2014). Tecnopolítica. El país.

Habermas, J. (2010). Teoría de la acción comunicativa. Tomo I. Racionalidad de la acción y racionalización social. Tomo II. Crítica de la razón funcionalista. Madrid: Editorial.

Harris, M. (2004). Antropología cultural. Madrid: Alianza Editorial.

Jenkins, H. (2003). Transmedia Storytelling. Moving characters from books to films to video games can make them stronger and more compelling. MIT Technology Review.

Kotler, P. y Armstrong, G. (2012). Marketing. Ciudad de México: Pearson.

Laufer, R. y Paradiese, C. (1990). Marketing Democracy: Public Opinion and Media Formation in Democratic Societies. New Brunswick: Transaction Press.

Maarek, P. (2009). Marketing político y comunicación. Barcelon: Paidós.

Mariñez Navarro, F. (2010). Ciencia Política. Nuevos contextos, nuevos desafíos. Ciudad de México: Editorial Limusa-Noriega.

Meyers, W. (1987). Los creadores de imagen: poder y persuasión en Madison Avenue. Barcelona: Planeta.

Moragas, M. (1979). Sociología de la comunicación de masas. Barcelona: Gustavo Gilli.

Newman, B. (1994). The Marketing of the President. Political Marketing as Campaign Strategy. Londres: Sage.

Norris, P. (2001). ¿Un círculo virtuoso? El impacto de las comunicaciones políticas en las democracias post-industriales. Revista Española de Ciencia Política, 4. 
Reyes, R., y Munch Galindo, L. (2003). Comunicación y mercadotecnia política. Ciudad de México: Editorial Noriega.

Sartori, G. (1992). Elementos de teoría política. Madrid: Editorial Alianza.

Sierra,F.(2007). Recuperadodehttps://idus.us.es/ xmlui/bitstream/handle/11441/13890/ file_1.pdf? sequence=1\&isAllowed=y.

Valdez, A. (2002). El ABC de la mercadotecnia política. Guadalajara: Universidad de Guadalajara.
Van Dijk, (2005). Política, ideología y discurso. Quorum Académico 2, Vol. 2, Universidad del Zulia. Recuperado el 4 de enero de 2018 de http://www.discursos.org/oldarticles/Politica\%20ideologia.pdf.

Vallespín, F. (2000). La crisis del espacio público. Revista Española de Ciencia Política, 3, 75-95.

Vallespín, F. (2012). La mentira os hará libres. Barcelona: Galaxia Gutenberg.

Williams, R. (2012). Sociología de la cultura. Madrid: Paidós. 